\title{
Cell-based fish: a novel approach to seafood production and an opportunity for cellular agriculture
}

\author{
Natalie Rubio ${ }^{1,2}$, Isha Datar ${ }^{2}$ David Stachura $^{3}$ and Kate Krueger ${ }^{2 *}$ \\ ${ }^{1}$ Department of Biomedical Engineering, Tufts University, Medford, MA, USA \\ ${ }^{2}$ New Harvest, Brooklyn, NY, USA \\ ${ }^{3}$ Department of Biological Sciences, Chico State University, Chico, CA, USA \\ Correspondence*: \\ Kate Krueger \\ kate@new-harvest.org
}

\begin{abstract}
Cellular agriculture is defined as the production of agricultural products from cell cultures rather than from whole plants or animals. With growing interest in cellular agriculture as a means to address the public health, environmental, and animal welfare challenges of animal agriculture, the concept of producing seafood from fish cell- and tissue-cultures is emerging as a means to address similar challenges with industrial aquaculture systems and marine capture.

Cell-based seafood - as opposed to animal-based seafood - can combine developments in biomedical engineering with modern aquaculture techniques. Biomedical engineering developments such as closed-system bioreactor production of land animal cells create a basis for large scale production of marine animal cells. Aquaculture techniques such as genetic modification and closed system aquaculture have achieved marked gains in production that can pave the way for innovations in cell-based seafood production.
\end{abstract}

Here, we present the current state of innovation relevant to the development of cellbased seafood across multiple species as well as specific opportunities and challenges that exist for advancing this science. The authors find that the physiological properties of fish cell- and tissue- culture may be uniquely suited to cultivation in vitro. These physiological properties, including hypoxia tolerance, high buffering capacity, and lowtemperature growth conditions, make marine cell culture an attractive opportunity for scale production of cell-based seafood; perhaps even more so than mammalian and avian cell cultures for cell-based meats. This, coupled with the unique capabilities of crustacean tissue-friendly scaffolding such as chitosan, a common seafood waste product and mushroom derivative, presents great promise for cell-based seafood production via bioreactor cultivation. To become fully realized, cell-based seafood research will require more understanding of fish muscle culture and cultivation; more investigation into serumfree media formulations optimized for fish cell culture; and bioreactor designs tuned to the needs of fish cells for large scale production.

Keywords: cellular agriculture, cell-based seafood, fish tissue culture, bioreactor, serum-free media, ocean conservation, marine cell culture, aquaculture

\section{INTRODUCTION}

The concept of producing meat from cell cultures rather than from slaughtered animal flesh has been proposed as a means to provide nutritional muscle tissue while addressing public health, animal welfare, and environmental issues associated with industrial animal agriculture (Datar and Betti 2010). The conversation around this concept has centered on the growth of mammalian or avian cells and tissues to replace meat, but cellular agriculture could easily be extended to piscine, molluscan, and crustacean cells and tissues to replace seafoods.

Aquaculture has recently surpassed marine capture as the main source of seafood for human consumption (Food, F.A.O. 2018). Global landings for marine capture have remained constant at around 90 million tonnes per year since 1994, while global aquaculture of fish and shellfish has nearly doubled in the same 


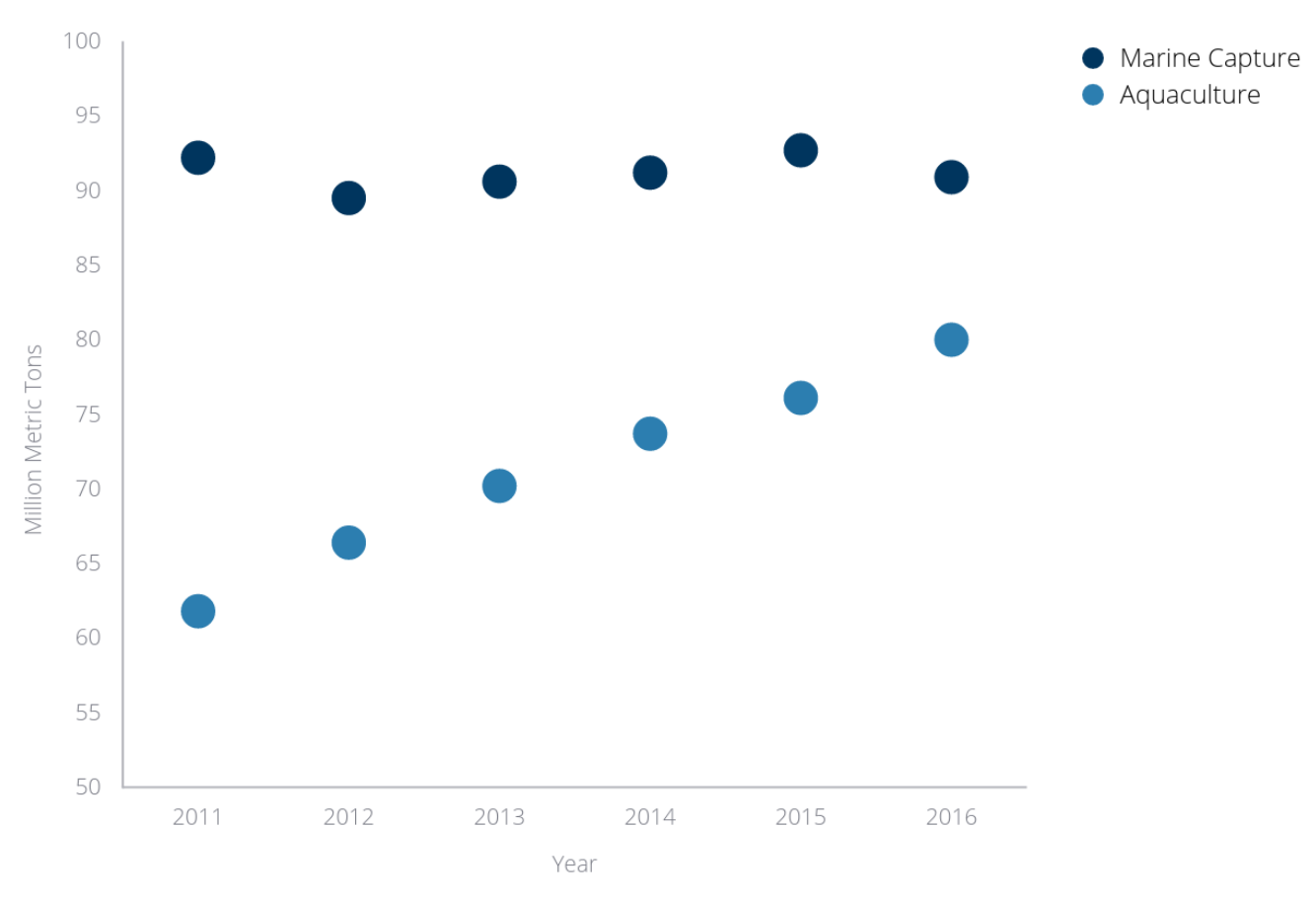

Figure 1. Global seafood production by marine capture and aquaculture by year from 2011 to 2016. Aquaculture production has increased while marine capture has remained fairly constant. Here, fish, crustaceans, molluscs and other aquatic animals are included, and aquatic mammals, crocodiles, caimans, seaweeds and other aquatic plants are excluded (Data adapted from the FAO. 2018. The State of World Fisheries and Aquaculture 2018 - Meeting the sustainable development goals. Rome. Licence: CC BY-NCSA 3.0 IGO)

time period (Food, F.A.O. 2018), indicating that aquaculture is not relieving the demand for wild-caught seafood (Naylor et al., 2000).

While aquaculture is often seen as mitigating overfishing, many farmed fish depend on feed originating from marine capture. Because several marine captured fish are used feed a single carnivorous farmed fish, some have argued that aquaculture is decreasing the global fish supply, rather than increasing it (Naylor and Burke, 2005).

\subsection{Trends in seafood production}

While aquaculture is a very old technology - pictorial engravings suggest that Egyptians aquacultured fish as early as $2500 \mathrm{BC}$ (Anon - FAO 1987)- it was only in the 1970s that aquaculture production became relevant beyond the subsistence and small scale (Asche et al, 2008). Similar to the evolution of agricultural land animal farming, aquaculture has moved from extensive systems, that depend on natural environments with minimal human intervention, to semi-intensive and intensive systems, where producers actively control growing conditions through feeding, breeding, disease control, waste removal, etc., resulting in much higher production rates (Asche et al., 2008)

With the intensification of aquaculture comes several challenges similar to the intensification of land animal husbandry. Intensification leads to greater production of nitrogen and phosphorus waste materials from uneaten feed and metabolic waste products (Yeo et al, 2004), thus creating higher risk of negative 
environmental impacts (Piedrahita, 2003), such as the damage of waterways and promotion of algal blooms (Paerl et al., 2014). Intensification also increases the risk of pathogen spread from farmed fish to native species (Naylor et al. 2000). Furthermore, an absence of research on the welfare of most aquacultured species has made it difficult to develop welfare standards for farmed aquatic animals, and thus the ethical implications and appropriate welfare regulations of aquaculture remain an open question (Browman et al, 2018).

While it is acknowledged that fully-controlled aquaculture environments are more efficient production systems than natural conditions (Tacon and Metian, 2008), there have, to date, been no mentions in the scientific literature about fully-controlled environments for producing seafood from cell cultures rather than from marine animal husbandry.

\subsection{Engineering biology for seafood production}

Genetic modification has resulted in spectacular production increases, feed conversion rates, and reduced development times for fish in closed systems (Muir 2004). Genetically-modified rohu develop over four times faster than their traditionally bred counterparts (Venugopal et al. 2004), while genetically-modified mud loaches are able to grow 35 times faster and substantially larger (Nam et al. 2001). Like the mud loach, genetically-modified tilapia containing the OPAFPcsGH gene can grow over 320 percent larger than similarly reared non-transgenic fish (Rahman et al. 1998). The OPAFPcsGH gene, which encodes for regulatory elements from ocean pout followed by growth hormone, forms the "all fish" chimera gene sequence used in Aquabounty salmon (Hew and Fletcher 1996). Aquabounty salmon, while approved for manufacture and sale in Canada, develop twice as fast as their wild type counterparts and sport an impressive feed conversion rate ten percent higher than farmed salmon (Bisson 2015). These fish are formidable food sources and an ecosystem threat - and thus are produced only in closed, in-land systems as triploid, and therefore infertile, females (Reichhardt 2000). Despite these safety measures, significant regulatory hurdles coupled with legislative pressure have prevented the fish from entering the US market (Waltz 2017). Regardless, the fish are a prime example of the power of engineering biology to improve closed-system seafood production. These genome-level advances for closed aquaculture systems may lay important groundwork for cell-based fish production research and development.

\section{CELL-BASED SEAFOOD PRODUCTION}

\subsection{The progression of cellular agriculture}

In the past five years, research focused on cell-based meats has accelerated from the tasting of the cell-cultured hamburger in 2013 (Zaraska 2013) and an early raft of publications, including life cycle assessments and basic research (Tuomisto and Teixeira de Mattos 2011; Post 2012; Post 2014), to a growing start-up community, updated life cycle assessments, and publications focused on refining the technologies required to accelerate cell-based meat production research (Tuomisto, Ellis, and Haastrup 2014; Krieger et al. 2018). To date, research decisions in cell-based meat production such as selection of cell species and cell type have been largely driven by market size and environmental impact (Rodríguez Fernández 2017), rather than suitability of cells species and types for large scale bioreactor cultivation. This is the result of a general lack of basic research on the cell cultures of commonly-consumed animals.

Cellular agriculture has recently become a topic of interest for regulators in the United States. Given the regulatory jurisdiction, broadly speaking, of the Food and Drug Administration over products of biotechnology and the United States Department of Agriculture over livestock, much interest has been given to the regulation necessary for potentially jurisdiction-blurring cell-based meat products (Stephens et al. 2018). Despite relative regulatory clarity over seafood, which is regulated entirely by the FDA (except for animals in the order Siluriformes) (Kobbeman 2004), cell-based seafood production, and its potential to address a growing demand for seafood while avoiding the challenges of industrial aquaculture, has remained relatively uninvestigated.

\subsection{Basic methodology for cell-based seafood production}

Like cell-based meat production, the production of cell-based seafood relies on advanced technological developments in cell line optimization, media formulation, and bioreactor design (Datar and Betti 2010). Like any closed cell- or tissue- culture system, a cell-based seafood production system would comprise of 
the following integrated elements: an appropriate cell type from the tissue of interest; a growth media to provide nutrients to proliferating and differentiating cells, and a bioreactor which would provide the closed environment in which growth would take place. For three-dimensional tissues, a biocompatible scaffold would offer structure for cell growth and maturation.

Bioreactors are complex closed-system environments for producing biomass that require the constant monitoring, maintenance, and optimization of several parameters. Marine cell cultures may be more forgiving compared to mammalian cell cultures, given the unique characteristics of native fish muscle tissue. This has significant implications for energy usage and thus cost considerations for mass production of cell-based seafood. It also presents a new set of research opportunities for cellular agriculture and large-scale tissue engineering as a whole.

\section{CHARACTERISTICS OF NATIVE FISH MUSCLE TISSUE COMPARED TO MAMMALIAN CELL CULTURE}

Disciplines such as bioengineering, cell biology, and genetics have made great gains in the understanding of cell- and tissue-culture the past twenty years - however these advances have been mostly within mammalian systems. Piscine and other marine animal tissues in vitro have not yet been adequately investigated.

Native fish muscle physiology, by contrast, is relatively well-researched because of the implications for aquaculture. Some experimentation and assaying has been carried out on harvested native muscle tissues from marine animals, and these studies provide interesting insights into the potential capabilities of fish muscle in culture.

Unlike mammalian muscle tissues, fish muscle in vivo consists of three muscle types - these muscles differ between species depending on fish type, location, and feeding strategy. In teleost and elasmobranch fish, there are three muscle types: red, white, and pink. Red muscle is highly vascularized with capillaries and comprised of slow twitch fibers with a high density of mitochondria and a rich supply of capillaries (Johnston 2001). This muscle is for slow, sustainable swimming speeds, and relies on aerobic metabolic pathways. White muscles are fast twitch, tightly packed with myofibrils, and primarily undergo anaerobic metabolic pathways. White muscle is used for burst-swimming and fast starts. Pink muscle shares some of the characteristics of white and red muscle (Johnston 2001).

The variety of fish muscle cell types, which vary in physiology and metabolic pathway, may offer a range of options when designing closed cultivation systems for cell-based seafood production. Native fish muscle also has a number of characteristics related to metabolism, described below, that, if mirrored in ex vivo tissue culture, renders it uniquely suited for cell-based production.

\subsection{Oxygen requirements}

\subsubsection{Of mammalian cell culture}

Low oxygen concentrations are detrimental to mammalian cell growth and bioproduct yield (Wang et al. 1994), and thus dissolved oxygen concentration and air saturation are important variables that must be monitored and maintained in bioreactor systems. Air saturation levels of 40 percent to 60 percent are often required for mammalian cell culture at scale (Furukawa and Ohsuye 1998; Link et al. 2004; Zhu et al. 2005). Air saturation and oxygen levels become even more critical in three-dimensional, thick vascularized tissues where oxygen diffusion limits the development of tissues past $1.8 \mathrm{~mm}$ (Griffith et al. 2005).

\subsubsection{Of fish}

As aquatic animals, fish are well adapted to tolerate low oxygen environments. Fish species are frequently subjected to low oxygen levels that result in hypoxic conditions (Vaquer-Sunyer and Duarte 2008). Interestingly, many coral reef fish are tolerant of hypoxic conditions as low as 2.8 to 0.5 percent air saturation for the goby Gobiodon histrio and 1.6 to 0.7 percent air saturation for the blenny Atrosalarias fuscus before showing signs of distress (Nilsson and Ostlund-Nilsson 2004). Using a microarray and bioinformaticsbased approach, Zhang and colleagues were able to identify over two hundred hypoxia-responsive genes in the Japanese medaka brain, gill, and liver ranging from cell metabolism to RNA processing to protein degradation through the ubiquitin system (Zhang et al. 2009). Hif1-alpha is a transcription factor that is present under hypoxic conditions - when molecular oxygen is present, the protein becomes hydroxylated 
and subsequently degraded by the ubiquitin system (Ivan et al. 2001). This highly tuned system, while discovered in mammals, plays a notable role in the hypoxia response of fish. Analysis of icefish mRNA revealed that the functional domains of Hif1-alpha are highly conserved indicating the continued selective pressure exerted by hypoxia (Rix, Grove, and O'Brien 2017). These and other hypoxia response gene relationships and predictions have been characterized in greater detail in the hypoxic fish database, HRGFish, available online, which provides a variety of prediction tools and validation methods to further evaluate the conservation of hypoxia genes in diverse fish species (Rashid et al. 2017)

In the absence of research on the oxygen requirements of fish cell culture in bioreactor systems, the authors speculate that the multitude of genetic adaptations of fish to staggering levels of hypoxia suggest that fish tissues may be uniquely suited to the oxygen-limited environments found in tissue culture and bioreactor conditions. Further, the presence of hypoxia response genes that are conserved in mammals suggest potential targets to increase mammalian cells' ability to tolerate low oxygen environments.

\section{$3.2 \mathrm{pH}$ considerations}

\subsubsection{Of mammalian cells}

Extracellular pH directly correlates with intracellular $\mathrm{pH}$ in mammalian cell culture (Lagadic-Gossmann, Huc, and Lecureur 2004), and lactic acid, which is formed by several cells in aerobic conditions (Brooks, 2009), accumulates over extended culture in bioreactor systems (Zhao and Ma 2005), contributing to acidification of the bioreactor environment. Because of the well-documented relationship between intracellular acidification and cell death (Lagadic-Gossmann, Huc, and Lecureur 2004), and because reduction of extracellular pH from 6.8 to 6.3 can render cells quiescent (Taylor and Hodson 1984), $\mathrm{pH}$ of bioreactor systems require fine tuning to optimize for cell growth.

Shifting $\mathrm{pH}$ can be used as an optimization tool, as changes in $\mathrm{pH}$ can affect protein production and glycosylation (Borys, Linzer, and Papoutsakis 1993), however altering $\mathrm{pH}$ to increase protein production and process performance reduces cell growth and metabolism (Trummer et al., 2006).

For mammalian cells cultures, the $\mathrm{pH}$ of a bioreactor system must be actively maintained to counter the build-up of acidic metabolites, and carefully optimized, for either cell proliferation or protein production, depending on the goals of the culture system.

\subsubsection{Of fish}

A key physiological characteristic of in vivo muscle across species is intracellular buffering capacity (Burton 1978). Buffering capacity is the ability of a cell to maintain a neutral $\mathrm{pH}$ in the presence of metabolic end products such as lactic acid (Rogatzki et al. 2015). It is measured in units of Slykes, the micromoles of base required to change the $\mathrm{pH}$ of homogenized tissue by one unit per gram of wet weight (Slyke 1922).

While land mammals such as pigs have buffering capacities of 49.7 Slykes, and cows of 51.9 Slykes, sea mammals such as the fur seal have buffering capacities of 79.2 Slykes, and spotted dolphins of 84.1 Slykes (Castellini and Somero 1981). White muscle in warm-bodied fishes have particularly high buffering capacity. Capacity was measured at 102 Slykes in the black skipjack, and 107 Slykes in the albacore double that of many land mammals (Castellini and Somero 1981). Further, muscle lactate dehydrogenase (LDH), the enzyme responsible for breaking down lactic acid in muscle tissues, has been shown to exhibit up to 2-fold higher activity in warm-bodied fish such as the albacore as compared to land animals such as the cow (Castellini and Somero 1981).

The higher intracellular buffering capacity and the higher muscle lactate dehydrogenase activity unique to warm bodied white fish muscle in vivo suggest that these muscle tissues may be more resilient than mammalian cells in vitro tissue culture, with an ability to grow optimally within a wider $\mathrm{pH}$ range. More research is required to determine if buffering capacity of native muscle tissue correlates to the buffering capacity of tissue cultured in vitro. 


\subsection{Temperature requirements}

\subsubsection{Of mammalian cells}

Mammalian cells in culture are often maintained at $37 \mathrm{C}$, human body temperature. This temperature is frequently used in mammalian bioreactor process design, however, temperature is a key variable that is often altered to optimize culture growth. Jenkins and Hovey obtained high viability by alternating culture temperatures between $39 \mathrm{C}$ and $34 \mathrm{C}$ (Jenkins and Hovey 1993), while others found that cultures grown under a specific regime at $30 \mathrm{C}$ can live longer and produce more protein (Moore et al. 1997).

\subsubsection{Of fish}

Fish vary widely in their adaptation strategies to frigid arctic and Antarctic environments, speciating at a higher rate near the earth's poles than near the equator (Rabosky et al. 2018). Some of these adaptations have resulted in the development of antifreeze defense systems that are best optimized for temperatures of 0-10 C (Abele and Puntarulo 2004) and increased production of antioxidants, such as marine derived tocopherol, which is found in greater quantities in salmon from cold waters than fish from equatorial waters (Yamamoto et al. 2001). Other adaptations include unique oxygen carrying and metabolism capabilities (Verde, Giordano, and di Prisco 2008). In some cases, these adaptations manifest as lack of hemoglobin altogether, as is the case in the demersal icefish, Chaenocephalus aceratus - these fish compensate for their lack of hemoglobin with increased numbers of mitochondria (Johnston 1987). Indeed, some have noted that adaptations in arctic species exhibit muscle design and mitochondrial density similar to high-performance adaptations in more equatorial species (Portner 2002).

Fish cell culture conditions typically mirror those of their typical habitats, with culture temperatures varying from $15 \mathrm{C}$ to $30 \mathrm{C}$. Some lines can vary their rate of metabolism within a 5-degree temperature span, with the cells metabolizing more quickly at higher temperatures (Courtenay and Williams 2004).

Because fish cells can be cultured at cooler temperatures, thus reducing 1) the energy required to maintain a constant temperature of a culture system, and therefore 2) the costs associated with producing cell-based seafood at scale, cell-based seafood may offer cost benefits at scale compared to cell-based meats.

\subsection{Fish cell lines}

Until the last decade fish cell lines have been used for limited applications - testing viral load, water toxicology, and generating vaccines for farmed fish. The American Type Culture Collection (ATCC), the premier online cell repository in the United States, contains over 4,000 cell lines, and maintains strict quality control on its collections, however, it does not contain any fish muscle cell lines (Hay, Caputo, and Macy 1992).

Few cell line databases include fish cell lines, however, two are of note: FICELdb and Cellosaurus. FICELdb is an unmaintained fish cell database that refers to many legacy lines dating from 1962 to 1999. Cellosaurus is a cell line compendium created in 2012 and published in 2018, housed within ExPASy, a database maintained Swiss Institute for Bioinformatics. It consists of cell line repositories from around the world, categorizing over 100,000 known cell lines (Artimo et al. 2012). Interestingly, only 558 are immortalized fish cell lines. Only nine are lines of fish cells were isolated from fish muscle, none of which are myoblastic, all of which have spontaneously immortalized (Bairoch 2018). The nine fish cell lines are displayed in the table below. Two of the nine fish cells lines originate from salt water species, both of which are epithelial in nature: a white sturgeon line spontaneously immortalized in 2003, and a bluefin trevally line from 2006. The cell line originating from barramundi, a euryhaline fish, is fibroblastic. The remaining six fish cell lines originate from fresh water species. Zebrafish Brachydanio rerio and Goldfish Carassius auratus are commonly-known model organisms and pets; the remaining cell lines originate from commonly cultivated species in Southeast Asia; the snakehead murrel, a common food fish in Thailand; the Sahul Indian catla, a farmed fish that is often grown with other carp species, and the helicopter catfish, a species farmed commercially in Malaysia.

While these nine cell lines have been useful for culturing a number of fish pathogens, none have yet been used for bioengineering or tissue engineering applications, and none are myoblastic lines. Derivation and characterization of myoblastic cell lines from various fish would be an important resource for researchers advancing cell-based seafood production. The availability of fish cell lines that are well-characterized to the 
level of a biological reagent could be a boon for cell-based seafood research; similar to what the availability of $\mathrm{C} 2 \mathrm{C} 12$ cells have done for mammalian muscle tissue engineering.

\begin{tabular}{llll}
\hline Cell Line & Publication & Morphology & Water \\
\hline White sturgeon & Wang et al. 2003 & Epithelial & Salt \\
Bluefin Trevally & Zhao and Lu 2006 & Epithelial & Salt \\
Barramundi & Lai et al. 2008 & Fibroblastic & Euryhaline \\
Zebrafish & Kumar et al. 2016 & Fibroblastic & Fresh \\
Goldfish & Rougée et al. 2007 & Epithelial & Fresh \\
Snakehead Murrel & Zhao et al. 2003 & Fibroblastic & Fresh \\
Indian Catla & Ishaq Ahmed et al. 2008 & Epithelial & Fresh \\
Indian Catla & Ishaq Ahmed et al. 2009 & Fibroblastic & Fresh \\
Helicopter catfish & unpublished & Unknown & Fresh \\
\hline
\end{tabular}

Table 1. Immortalized fresh water fish muscle-isolated cell lines with relevant characteristics and publications from Cellosaurus.

\subsection{Cell isolation methods}

Because of the lack of fish cell lines, much fish tissue culture work is conducted on primary tissue cultures isolated from fish.

Fish cell isolation methods are similar in many respects to mammalian cell isolations. In general, the fish is bathed in ethanol, anesthetized, and a tissue sample is removed with a biopsy. The tissue sample is then either explanted or enzymatically-digested with collagenase or trypsin. Explanted tissues are allowed to attach to the culture plate, and cells migrate from the tissue to the culture surface. Enzymatically-digested tissues are in aqueous solutions, where digestion by trypsin or collagenase releases cells into the liquid medium. Cells are then rinsed with buffer to remove contaminants and are often filtered to liberate the cells from residual debris. Enzymatic digestion is often preferred for muscle cells.

While these techniques work well for isolating tissue from adult fish, recent research has begun investigating the isolation of cells from embryonic teleosts. While embryonic cells from many wild species are hard to isolate, it is not impossible, especially from farmed strains and wild fish that are artificially fertilized at fish hatcheries. Additionally, many species of fish have high telomerase activity, so primary embryonic cells do not senesce as quickly as in mammalian systems (Anchelin et al., 2011). Importantly, while fish do not have embryonic stem cells per se, they do have embryonic progenitors that may be coaxed down different differentiation pathways (Ciarlo et al., 2017; Ma et al., 2001; Chandramallika et al., 1997).

As more research is done on fish muscle cell types, it will also be possible to isolate populations of interest from either adult or embryonic cell preparations. Magnetic beads coupled to muscle-progenitor-specific antibodies will allow rapid isolation of these cells. Additionally, fluorescence-activated cell sorting (FACS) is an effective technique for cell isolation. The main challenge is identifying cell-surface proteins that mark these progenitors and muscle cells; the conservation with extracellular proteins with mammals is very low (Liongue and Ward, 2007), so most mammalian antibodies do not cross-react.

\subsection{Culture conditions}

\subsubsection{Extracellular environments and scaffolds}

Future work determining the correct extracellular matrix (ECM) that these fish cells survive and proliferate on is of utmost importance; most mammalian cell lines are simply plated on tissue-culture plates coated with vacuum gas plasma, which makes the polystyrene surface more hydrophilic. Fish cells may require scaffolds of different ECM proteins such as elastins, collagens, fibronectin, and laminin to adhere and grow efficiently, and may also require fish glycoaminoglycans. Optimizing these ECM proteins would also likely be critical to efficient fish culture in vitro, especially since fish protein glycosylation patterns are different from mammals. 


\subsection{Growth media}

Parameters for fish cell culture growth media include salt concentration, buffer, temperature, and $\mathrm{pH}$. Past growth media formulas suggest a trial and error approach that may not be optimal for all species or purposes. Previous publications used growth media that include mammalian formulations such as Eagle's Medium, Modified Eagle's Medium (MEM), Medium 199 (M199) and Leibowitz's 15 (L-15) medium (Fernandez et al. 1993). These media are fully defined and easily replicated, including inorganic salts, amino acids, and basic nutrients for culture growth. Additional salts are added for some marine species such as the grunt, but not all (Clem, Moewus, and Michael Sigel 1961). Fetal bovine serum (FBS) and fetal calf serum (FCS) are common additives. Use of bicarbonate in media formulations aids cell growth and buffering capabilities as well (Fernandez et al. 1993). This ability to control the buffering capacity of the media is important; some fish cells require growth at 5 percent carbon dioxide, but others are fine in anoxic or standard oxygen tension. These conditions vary between species (and even between tissues from the same fish) but can be controlled for the purposes of cell-based seafood production. Addition of growth factors, such as fibroblast growth factor (FGF2) has proven helpful to the growth of some muscle cell cultures. Bain and Schuller reported successful culture of epithelial tuna cells in L-15 media with 10-20 percent FBS (Bain et al. 2013). Attempts to lower the FBS content resulted in reduced cell proliferation, but the addition of vitamin E and fatty acids improved proliferation. (Scholefield and Schuller 2014).

Clearly, removing FBS or FCS from the media for cell-based seafood productions would be advantageous due to the high cost of these products, their animal sources, and their potential for carrying mammalian viruses and prions. Investigations into the molecular components of fish serum would likely be useful to identify and then generate in vitro the required components to keep fish cells alive and dividing in culture. Furthermore, fats are nutritionally-relevant in seafood, and more research can be done to understand how media composition can affect the nutritional quality of a cell-based seafood.

\section{CRUSTACEAN CELL CULTURE}

\subsection{Cell lines}

In recent decades, crustacean cell culture research has been explored for use in the aquaculture and pharmaceutical industries (Zhao et al. 2003), for studying diseases affecting farmed seafood and identifying biologics with human clinical relevance. Several studies have attempted to establish cell lines from crustacean tissues to improve isolation and maintenance methodology, however, in recent decades there has been a decrease in effort to develop long-term cultures and instead research has proceeded with the use of short-term cultures obtained from repeated primary cell isolations (Rinkevich 2005). Short-term cultures are sufficient for bench-scale research but not sufficient for cell-based seafood applications with long-term goals of mass production and commercialization.

To advance crustacean tissue culture for food purposes, it is vital to attempt new strategies for developing immortalized or long-term cell lines of relevant lineages such as muscle and fat. Previous crustacean tissue culture studies have instead focused for ovary-derived epithelial and fibroblast cells. The studies that examined muscle, eye stalk, and hepatopancreas cells in crustaceans found they have poorer survival and slower growth compared to ovary-derived epithelial and fibroblast cells (George and Dhar 2010). The most frequently studied crustacean genus is Penaeus which includes shrimp and prawn species. Studies of this species have derived cells from ovary, hepatopancreas, nerve, lymphoid and hematopoietic tissue (Rinkevich 2005).

Much more work is to be done to derive and characterize crustacean cells to the level of a biological reagent so that they may be used for cell-based seafood research and development. It is possible that establishment of such cell lines could also be relevant to the aquaculture and pharmaceutical sectors.

\subsection{Cell isolation methods}

Cell isolation procedures for crustaceans and vertebrates share several similarities. For example, Tong and Miao found that cells isolated from younger "pre-molting" prawns have a higher success rate for survival and growth (Tong and Miao 1996). Cell cultivation studies often attempt isolations from both explanted and enzyme-digested tissues. For the explant method, which is best suited for loose tissues, the target tissue is removed from the animal, rinsed in custom buffer solution, dissected into small sections and allowed to attach to a culture surface. If successful, cells within the tissue will proliferate, migrate, and 
adhere to the substrate. For the enzyme digestion method, digestion enzymes (e.g., trypsin, collagenase) are incubated with dissected explants to degrade the tissue into a single cell suspension. The slurry is often filtered to remove undigested sections and the enzymes are inhibited after a certain amount of incubation time to prevent cell damage. For cell isolations from most shrimp tissues, the explant method tends to have more success than enzyme-digested method in terms of cell proliferation, although enzyme digestion is preferred for hepatopancreas tissues (Ma, Zeng, and Lu 2017).

\subsection{Culture conditions}

Parameters such as temperature, $\mathrm{pH}$ and osmolality differ between vertebrate and invertebrate cell culture. The incubation temperature for invertebrates is lower than for vertebrates and typically falls within the range of $25-30{ }^{\circ} \mathrm{C}$. The $\mathrm{pH}$ of shrimp and prawn cell cultures is typically within the range of 7.0-7.6 (Ma, Zeng, and Lu 2017). Osmolality can range between 472-760 mmol/kg depending on the hemolymph osmolality of the origin animal (Chen et al. 1986; Rinkevich 2005). Carbon dioxide exchange is generally not necessary for invertebrate culture because the basal media tends to be buffered by phosphates rather than sodium bicarbonate. While cells have been observed to reach confluency and survive for extended periods of time with media changes once-per-week, the cultures often degenerate after a few rounds of subculture (Chen et al. 1986; Ma, Zeng, and Lu 2017). This may be due to high sensitivity of the cells to the enzymes such as trypsin which are employed during passaging.

Like fish cells, crustacean cells can be cultured at lower temperatures, suggesting an energy saving opportunity for large scale bioreactor culture compared to mammalian cells. Similarly, crustacean cell culture does not require carbon dioxide exchange, obviating the need for a common mammalian cell culture bioreactor parameter.

\subsection{Growth media}

The basal medium for invertebrate cell culture commonly consists of Grace's medium or L-15 medium, though formulations such as M199 have at times exhibited superior effects (Ma, Zeng, and Lu 2017). The standard for mammalian cell culture is basal media supplemented with animal serum from domestic species like cows, horses or chickens. Fetal bovine serum is also important for shrimp cell culture at a concentration of ten to twenty percent (Ma, Zeng, and Lu 2017). However, this strategy has not been sufficient to maintain crustacean cells in culture long-term, so researchers have attempted to supplement media with marine-relevant factors such as lipid solutions or hemolymph extracted from various sea creatures (Chen et al. 1986; Rinkevich 2005). Common supplements include shrimp or crab muscle extract and hemolymph from Penaeus species. These additions likely provide growth factors not supplied by mammalian serum. Some growth factors have been identified to improve shrimp lymphoid and ovarian cultures, like epidermal growth factor and transforming growth factor beta (Ma, Zeng, and Lu 2017).

Much more work is needed in the development of a sustainable, animal-free media for the growth of crustacean cells. It is likely that animal-based media are used merely because a lack of well-researched options.

\section{BIVALVE CONSIDERATIONS}

\subsection{Buffering capacity}

Observed buffering capacity varies widely in mollusks (Eberlee and Storey 1984) with some species exhibiting a particularly high buffering capacity. The channeled whelk, Busycotypus canaliculatus, has been shown to have an aerobic buffering capacity in the hepatopancreas of 79.4 plus or minus 17.2 Slykes, and a remarkable buffering capacity of almost 120 Slykes following 24 hours of anoxic stress (Hetrick et al. 1981). While heart muscle tissues appear to have lower buffering capacity, anoxic stress increases their buffering capacity to over 60 Slykes (Eberlee and Storey 1984) - still higher than that of many land animals.

The high buffering capacity of bivalves suggests an ability of bivalve cell culture to tolerate a wider $\mathrm{pH}$ range than mammalian cell cultures. 


\subsection{Cell culture}

Bivalve culture has proven even more elusive than fish or crustacean culture. While many have attempted to continuously culture a bivalve cell line, very few have been able to achieve proliferation (Chen and Wang 1999). Researchers at the University of Maryland were unable to successfully achieve mitosis in any of their long-term cultures of clam and oyster lines attempted, in spite of 138 unique attempts in different media formulations (Hetrick et al. 1981). Odinstova and colleagues observed low, though extant, mitotic activity in scallop culture over a period of four months (Odintsova and Khomenko 1991). Similarly, mitosis in the surf clam, Spisula soldissima was observed, though media contained fetal calf serum and whole egg extract (Cecil 1969). Despite challenges with proliferation in culture, many primary cell cultures have been generated (Chen and Wang 1999).

An exception to the aforementioned lack of proliferative cultures are cell cultures from abalone species cultivated for pearl production and hemocyte (blood cell) lines that can be used for toxicological studies. Mantle of Haliotis varia in Medium 199 containing additional salts, lactalbumin, kanamycin, and sodium bicarbonate, and fetal bovine serum, has been successfully cultured for 370 days (Suja and Dharmaraj 2005). The authors more recently were able to culture the mantle of Haliotis varia in serum free media containing a whole-body extract (Suja, Sukumaran, and Dharmaraj 2007).

Even fewer bivalve muscle cells have been isolated. Clam primary cardiomyocytes that could be grown for up to a month have been isolated(Hanana et al. 2011) and primary culture of clam heart tissue originating from Meretrix luxoria was successfully cultured for over five months (Chen and Wang 1999).

Bivalve cell culture is understudied, with demonstrated challenges in establishing long term, proliferative, food-relevant cell lines.

\section{SCAFFOLDS FOR THREE-DIMENSIONAL TISSUE CULTIVATION}

Cultivating three-dimensional tissues relies on the presence of a scaffold - a biocompatible material capable of supporting cell growth and differentiation. While there are several scaffolding materials employed in tissue engineering today, we discuss chitosan, a food-relevant material that is derived from chitin; a primary component of insect and crustacean exoskeletons and one of the most prevalent biopolymers on earth alongside cellulose. Within exoskeletons, chitin exists as nanofibril structures, providing mechanical strength to the cuticle. Chitosan can also be derived from non-animal sources like fungi, algae and yeast. As collagen and other extracellular matrix proteins prove to be successful scaffold biomaterials for mammalian tissue engineering, it is reasonable (once cell lines are sufficiently available) to employ chitosan scaffolding techniques as a first step towards three-dimensional culture of seafood-relevant cell types. Due to the mechanical characteristics of chitosan, it is a popular biomaterial for scaffold construction for many applications of tissue engineering. Chitosan powder can be isolated from crustacean, mushroom or microbial sources and dissolved into an aqueous solution which can be cast into a variety of formats such as membranes, hydrogels and sponges (Croisier and Jérôme 2013). Fungal chitosan is a preferred source as it is (1) non-allergenic, (2) more customizable in terms of molecular weight and (3) approved for human consumption as a food additive or nutrition supplement (Pochanavanich and Suntornsuk 2002; Tao Wu et al. 2004; Nitschke et al. 2011).

\subsection{Scaffold fabrication}

Chitosan can be dissolved in acidic solution such as 1-2 percent acetic acid in distilled water. Agitation and heat both promote dissolution. As the concentration of dissolved chitosan increases, the solution becomes increasingly viscous. With time and patience, solutions of 12 percent chitosan can be achieved if desired (Jana, Cooper, and Zhang 2013). Many scaffolds that support various cell cultures use lower chitosan concentrations. Solutions with concentrations as low as 0.5 percent chitosan are able to produce thin membranes with remarkable mechanical strength. To create films for cell culture, chitosan solution is cast on glass substrates and allowed to dry. The films are subsequently rinsed with buffer to neutralize remaining acetyl groups, washed with water or PBS and sterilized to prepare for seeding. Chitosan can also be manipulated to produce physically associated or cross-linked hydrogels (Drury and Mooney 2003), sponges with tunable mechanical properties and pore size distributions (Jana, Cooper, and Zhang 2013) and dry or wet spun fibers (Croisier and Jérôme 2013). 


\section{DISCUSSION}

Given the progression of aquaculture towards more intensive, more controlled, more efficient systems, the authors propose cell-based seafood production as a means to potentially avert the challenges of industrial aquaculture and displace marine capture.

This review presents opportunities for cell-based seafood production research by surveying the literature on marine cell culture, native marine muscle tissue, and marine animal considerations which may be directly relevant or adjacent to the development of a cell-based seafood production system. Because of the minimal availability of literature on marine cell cultures, the authors speculated on the characteristics of marine cell culture based on the unique properties of native muscle tissue in fish.

Overall, it appears that fish muscle tissue may be innately well-suited for bioreactor cultivation relative to mammalian muscle tissues, given the ability of fish tissues to 1) endure hypoxic conditions, reducing the need for active oxygenation in oxygen-limited bioreactor environments; 2) tolerate $\mathrm{pH}$, potentially creating a wider range of $\mathrm{pH}$ in which cell growth is optimized; and 3) grow at lower temperatures, potentially reducing the heat transfer needs of bioreactor cultivation at scale.

A review of the literature on crustacean cell culture indicates that there is very little research that is directly relevant for cell-based food production; most research is adjacent, either from species that are not directly food-relevant, or cell-types that are not directly food-relevant. A review of the literature on bivalves is even more sparse.

Approaches to cell-based seafood production can range from large scale cell cultivation, resulting in a large mass of seafood-relevant cells that may have applications in processed seafoods like surimi; to three-dimensional tissue cultivation, resulting in structured products more akin to fillets. Chitosan is a promising, marine-relevant biomaterial for three-dimensional tissue culture applications. It is customizable, edible, and widely available; making it a suitable material to explore for cell-based seafood production, as well as other tissue engineering and cellular agriculture applications.

There could be several advantages to producing seafood from cell cultures rather than whole marine animals. The production of cell-based seafood has the distinct potential to alter many of the fundamental parameters considered immutable in food cultivation, including production of inedible excess tissues such as bone, skin, shells, and scales. It is also possible that cell-based seafood could be produced from cell cultures on the order of weeks to months; by comparison, a genetically-modified Aquabounty salmon grows to market size in 18 months, roughly half the time of a normal salmon (Waltz, 2017).

\section{CONCLUSIONS}

Producing seafood from marine cell cultures is a novel seafood production method and an intriguing opportunity for cellular agriculture.

A survey of relevant literature reveals that marine cell and tissue culture is an enormously neglected field of research. Very few cell lines from marine species have been derived and characterized, and none are directly relevant to seafood production. Despite the several properties of marine muscle tissue that make it promising for bioreactor cultivation, the actual behavior of marine cells in large scale culture environments remains speculative. There are several research gaps that exist for marine cell culture, alongside several opportunities that make these research gaps worth addressing.

With growing interest in cellular agriculture as a means to produce meat, milk, eggs, and other animal proteins from cell cultures, and with the rapid intensification of aquaculture systems, the time is right to investigate the production of seafood without marine animals.

\section{AUTHOR CONTRIBUTIONS}

Kate Krueger oversaw the preparation and writing of the manuscript and themes, contributing sections on bivalve cell culture, and oxygen and $\mathrm{pH}$ considerations. Natalie Rubio contributed material on crustacean cell culture, and David Stachura contributed to fish tissue isolation, embryonic cells, and muscle cell type sections. Isha Datar contributed to the organization, writing and editing of the manuscript. 


\section{CONFLICT OF INTEREST STATEMENT}

The authors declare that the research was conducted in the absence of any commercial or financial relationships that could be construed as a potential conflict of interest.

\section{FUNDING}

New Harvest is a 501(c)(3) research institute that supports basic research in cellular agriculture The research for this review was performed using funding to New Harvest from an anonymous donor.

\section{ACKNOWLEDGEMENTS}

The authors would like to acknowledge Bradley Silverman for his insights on process engineering considerations, Arif Malik for his insights on the fish musculature section of this review, Andrew Stout for his insights on the Warburg effect, and Mike Selden for his introductions and support.

\section{REFERENCES}

Abele, D., and Puntarulo, S. (2004). Formation of reactive species and induction of antioxidant defence systems in polar and temperate marine invertebrates and fish. Comparative Biochemistry and Physiology Part A: Molecular \& Integrative Physiology 138, 405-415.

Anchelin, M., Murcia, L., Alcaraz-Pérez, F., García-Navarro, E. M., and Cayuela, M. L. (2011). Behaviour of Telomere and Telomerase during Aging and Regeneration in Zebrafish. PLoS One 6. doi:10.1371/journal.pone.0016955.

Artimo, P., Jonnalagedda, M., Arnold, K., Baratin, D., Csardi, G., De Castro, E., et al. (2012). ExPASy: SIB bioinformatics resource portal. Nucleic acids research 40, W597-W603.

Asche, F., Roll, K. H., and Tveterås, S. (2008). "Future Trends in Aquaculture: Productivity Growth and Increased Production," in Aquaculture in the Ecosystem, eds. M. Holmer, K. Black, C. M. Duarte, N. Marbà, and I. Karakassis (Dordrecht: Springer Netherlands), 271-292. doi:10.1007/978-1-4020-6810-2_9.

Bain, P. A., Hutchinson, R. G., Marks, A. B., Crane, M. S. J., and Schuller, K. A. (2013). Establishment of a continuous cell line from southern bluefin tuna (Thunnus maccoyii). Aquaculture 376, 59-63.

Bairoch, A. (2018). The Cellosaurus, a Cell-Line Knowledge Resource. Journal of biomolecular techniques: JBT.

Bisson, R. (2015). AquaBounty: label the salmon, for everyone's sake. The Guardian. Available at: https://www.theguardian.com/sustainable-business/2015/dec/21/aquabounty-salmon-fda-gmo-foodslabeling [Accessed September 7, 2018].

Borys, M. C., Linzer, D. I. H., and Papoutsakis, E. T. (1993). Culture pH Affects Expression Rates and Glycosylation of Recombinant Mouse Placental Lactogen Proteins by Chinese Hamster Ovary (CHO) Cells. Nature Biotechnology 11, 720-724. doi:10.1038/nbt0693-720.

Brooks, G. A. (2009). Cell-cell and intracellular lactate shuttles. The Journal of Physiology 587, 5591-5600. doi:10.1113/jphysiol.2009.178350.

Browman, H. I., Cooke, S. J., Cowx, I. G., Derbyshire, S. W. G., Kasumyan, A., Key, B., et al. Welfare of aquatic animals: where things are, where they are going, and what it means for research, aquaculture, recreational angling, and commercial fishing. ICES J Mar Sci. doi:10.1093/icesjms/fsy067.

Burton, R. F. (1978). Intracellular buffering. Respiration Physiology 33, 51-58. doi:10.1016/00345687(78)90083-X.

Castellini, M. A., and Somero, G. N. (1981). Buffering capacity of vertebrate muscle: Correlations with potentials for anaerobic function. J Comp Physiol B 143, 191-198. doi:10.1007/BF00797698.

Cecil, J. T. (1969). Mitoses in cell cultures from cardiac tissue of the surf clam Spisula solidissima. J. Invertebr. Pathol. 14, 407-410.

Chen, S. N., CHI, S.-C., Kou, G. H., and Liao, I. C. (1986). Cell culture from tissues of grass prawn, Penaeus monodon. Fish pathology 21, 161-166. 
Chen, S. N., and Wang, C. S. (1999). Establishment of cell lines derived from oyster, Crassostrea gigas Thunberg and hard clam, Meretrix lusoria Röding. Methods Cell Sci 21, 183-192. doi:10.1023/A:1009829807954.

Ciarlo, C., Kaufman, C. K., Kinikoglu, B., Michael, J., Yang, S., D’Amato, C., et al. A chemical screen in zebrafish embryonic cells establishes that Akt activation is required for neural crest development. eLife 6. doi:10.7554/eLife.29145.

Courtenay, P. W. R., and Williams, J. D. (2004). Snakeheads (Pisces, Channidae): A Biological Synopsis and Risk Assessment. United States Geological Survey.

Croisier, F., and Jérôme, C. (2013). Chitosan-based biomaterials for tissue engineering. European Polymer Journal 49, 780-792. Drury, J. L., and Mooney, D. J. (2003). Hydrogels for tissue engineering: scaffold design variables and applications. Biomaterials 24, 4337-4351.

Eberlee, J. C., and Storey, K. B. (1984). Buffering Capacities of the Tissues of Marine Molluscs. Physiological Zoology 57, 567-572. Available at: https://www.jstor.org/stable/30163950 [Accessed September 3, 2018].

FAO. 2018. The State of World Fisheries and Aquaculture 2018 - Meeting the sustainable development goals. Rome. Licence: CC BY-NC-SA 3.0 IGO.

Fernandez, R. D., Yoshimizu, M., Ezura, Y., and Kimura, T. (1993). Comparative growth response of fish cell lines in different media, temperatures, and sodium chloride concentrations. Fish Pathology 28, 27-34.

Food, F. A. O. (2018). The State of World Fisheries and Aquaculture 2018. Contributing to Food Security and Nutrition for All.

Furukawa, K., and Ohsuye, K. (1998). Effect of culture temperature on a recombinant CHO cell line producing a C-terminal $\alpha$-amidating enzyme. Cytotechnology 26, 153-164.

George, S. K., and Dhar, A. K. (2010). An improved method of cell culture system from eye stalk, hepatopancreas, muscle, ovary, and hemocytes of Penaeus vannamei. In Vitro Cellular \& Developmental Biology-Animal 46, 801-810.

Ghosh, C., Liu, Y., Ma, C., and Collodi, P. (1997). Cell cultures derived from early zebrafish embryos differentiate in vitro into neurons and astrocytes. Cytotechnology 23, 221-230. doi:10.1023/A:1007915618413.

Glacken, M. W., Fleischaker, R. J., and Sinskey, A. J. (1986). Reduction of waste product excretion via nutrient control: Possible strategies for maximizing product and cell yields on serum in cultures of mammalian cells. Biotechnol. Bioeng. 28, 1376-1389. doi:10.1002/bit.260280912.

Griffith, C. K., Miller, C., Sainson, R. C. A., Calvert, J. W., Jeon, N. L., Hughes, C. C. W., et al. (2005). Diffusion limits of an in vitro thick prevascularized tissue. Tissue Eng. 11, 257-266. doi:10.1089/ten.2005.11.257.

Hanana, H., Talarmin, H., Pennec, J. P., Droguet, M., Gobin, E., Marcorelle, P., et al. (2011). Establishment of functional primary cultures of heart cells from the clam Ruditapes decussatus. Cytotechnology 63, 295-305. doi:10.1007/s10616-011-9347-8.

Hay, R. J., Caputo, J., and Macy, M. L. (1992). ATCC quality control methods for cell lines. Amer Type Culture Collection.

Hetrick, F. M., Stephens, E., Lomax, N., and Lutrell, K. (1981). Attempts to develop a marine molluscan cell line. College Park, University of Maryland. Sea Grant College Program Technical Report UM-SG-TS81-06.

Hew, C. L., and Fletcher, G. L. (1996). Transgenic salmonid fish expressing exogenous salmonid growth hormone. INTRODUCTION TO AQUACULTURE Available at: http://www.fao.org/docrep/field/003/ac 169e/ac169e00.htm [Accessed October 4, 2018].

Ivan, M., Kondo, K., Yang, H., Kim, W., Valiando, J., Ohh, M., et al. (2001). HIFalpha targeted for VHL-mediated destruction by proline hydroxylation: implications for O2 sensing. Science 292, 464-468. doi:10.1126/science.1059817. 
Jana, S., Cooper, A., and Zhang, M. (2013). Chitosan scaffolds with unidirectional microtubular pores for large skeletal myotube generation. Advanced healthcare materials 2, 557-561.

Jenkins, N., and Hovey, A. (1993). Temperature control of growth and productivity in mutant Chinese hamster ovary cells synthesizing a recombinant protein. Biotechnol. Bioeng. 42, 1029-1036. doi:10.1002/bit.260420903.

Johnston, I. A. (1987). Respiratory characteristics of muscle fibres in a fish (Chaenocephalus aceratus) that lacks haem pigments. Journal of experimental Biology 133, 415-428.

Johnston, I. A. (2001). Fish Physiology: Muscle Development and Growth. Gulf Professional Publishing.

Krieger, J., Park, B.-W., Lambert, C. R., and Malcuit, C. (2018). 3D skeletal muscle fascicle engineering is improved with TGF- $\beta 1$ treatment of myogenic cells and their co-culture with myofibroblasts. PeerJ 6 , e4939.

Lagadic-Gossmann, D., Huc, L., and Lecureur, V. (2004). Alterations of intracellular pH homeostasis in apoptosis: origins and roles. Cell death and differentiation 11, 953.

Le, H., Kabbur, S., Pollastrini, L., Sun, Z., Mills, K., Johnson, K., et al. (2012). Multivariate analysis of cell culture bioprocess data-Lactate consumption as process indicator. Journal of Biotechnology 162, 210-223. doi:10.1016/j.jbiotec.2012.08.021.

Link, T., Bäckström, M., Graham, R., Essers, R., Zörner, K., Gätgens, J., et al. (2004). Bioprocess development for the production of a recombinant MUC1 fusion protein expressed by CHO-K1 cells in protein-free medium. Journal of biotechnology 110, 51-62.

Liongue, C., and Ward, A. C. (2007). Evolution of class I cytokine receptors. BMC evolutionary biology 7, 120.

Ma, C., Fan, L., Ganassin, R., Bols, N., and Collodi, P. (2001). Production of zebrafish germ-line chimeras from embryo cell cultures. Proc Natl Acad Sci U S A 98, 2461-2466. doi:10.1073/pnas.041449398.

Ma, J., Zeng, L., and Lu, Y. (2017). Penaeid shrimp cell culture and its applications. Reviews in Aquaculture 9, 88-98.

'Meat' the Founder behind the Lab-Grown Burger Investors are Queuing for (2017). Labiotech.eu. Available at: https://labiotech.eu/interviews/interview-mark-post-cultured-meat/ [Accessed October 4, 2018].

Moore, A., Mercer, J., Dutina, G., Donahue, C. J., Bauer, K. D., Mather, J. P., et al. (1997). Effects of temperature shift on cell cycle, apoptosis and nucleotide pools in $\mathrm{CHO}$ cell batch cultues. Cytotechnology $23,47-54$.

Muir, W. M. (2004). The threats and benefits of GM fish. EMBO Rep 5, 654-659. doi:10.1038/sj.embor.7400197.

Nam, Y. K., Noh, J. K., Cho, Y. S., Cho, H. J., Cho, K. N., Kim, C. G., et al. (2001). Dramatically accelerated growth and extraordinary gigantism of transgenic mud loach Misgurnus mizolepis. Transgenic Res. 10, 353-362.

Naylor, R., and Burke, M. (2005). Aquaculture and ocean resources: raising tigers of the sea. Annu. Rev. Environ. Resour. 30, 185-218.

Naylor, R. L., Goldburg, R. J., Primavera, J. H., Kautsky, N., Beveridge, M. C., Clay, J., et al. (2000). Effect of aquaculture on world fish supplies. Nature 405, 1017.

Nilsson, G. E., and Ostlund-Nilsson, S. (2004). Hypoxia in paradise: widespread hypoxia tolerance in coral reef fishes. Proc. Biol. Sci. 271 Suppl 3, S30-33. doi:10.1098/rsbl.2003.0087.

Nitschke, J., Altenbach, H.-J., Malolepszy, T., and Mölleken, H. (2011). A new method for the quantification of chitin and chitosan in edible mushrooms. Carbohydrate research 346, 1307-1310.

Odintsova, N. A., and Khomenko, A. V. (1991). Primary cell culture from embryos of the Japanese scallop Mizuchopecten yessoensis (Bivalvia). Cytotechnology 6, 49-54. 
Paerl, H. W., Gardner, W. S., McCarthy, M. J., Peierls, B. L., and Wilhelm, S. W. (2014). Algal blooms: Noteworthy nitrogen. Science 346, 175-175. doi:10.1126/science.346.6206.175-a.

Piedrahita, R. H. (2003). Reducing the potential environmental impact of tank aquaculture effluents through intensification and recirculation. Aquaculture 226, 35-44. doi:10.1016/S0044-8486(03)00465-4.

Pochanavanich, P., and Suntornsuk, W. (2002). Fungal chitosan production and its characterization. Letters in applied microbiology 35, 17-21.

Pörtner, H.-O. (2002). Climate variations and the physiological basis of temperature dependent biogeography: systemic to molecular hierarchy of thermal tolerance in animals. Comparative Biochemistry and Physiology Part A: Molecular \& Integrative Physiology 132, 739-761.

Post, M. J. (2012). Cultured meat from stem cells: Challenges and prospects. Meat science 92, 297-301.

Post, M. J. (2014). An alternative animal protein source: cultured beef. Annals of the New York Academy of Sciences 1328, 29-33.

Rabosky, D. L., Chang, J., Title, P. O., Cowman, P. F., Sallan, L., Friedman, M., et al. (2018). An inverse latitudinal gradient in speciation rate for marine fishes. Nature 559, 392-395. doi:10.1038/s41586-0180273-1.

Rahman, M. A., Mak, R., Ayad, H., Smith, A., and Maclean, N. (1998). Expression of a novel piscine growth hormone gene results in growth enhancement in transgenic tilapia (Oreochromis niloticus). Transgenic Res. 7, 357-369.

Rashid, I., Nagpure, N. S., Srivastava, P., Kumar, R., Pathak, A. K., Singh, M., et al. (2017). HRGFish: A database of hypoxia responsive genes in fishes. Scientific Reports 7, 42346. doi:10.1038/srep42346.

Reichhardt, T. (2000). Will souped up salmon sink or swim?. Nature Publishing Group.

Rinkevich, B. (2005). Marine invertebrate cell cultures: new millennium trends. Marine biotechnology 7 , 429-439.

Rix, A. S., Grove, T. J., and O'Brien, K. M. (2017). Hypoxia-inducible factor- $1 \alpha$ in Antarctic notothenioids contains a polyglutamine and glutamic acid insert that varies in length with phylogeny. Polar Biol 40, 2537-2545. doi:10.1007/s00300-017-2164-6.

Rogatzki, M. J., Ferguson, B. S., Goodwin, M. L., and Gladden, L. B. (2015). Lactate is always the end product of glycolysis. Front Neurosci 9. doi:10.3389/fnins.2015.00022.

Scholefield, A. M., and Schuller, K. A. (2014). Cell proliferation and long chain polyunsaturated fatty acid metabolism in a cell line from southern bluefin tuna (Thunnus maccoyii). Lipids 49, 703-714.

Slyke, D. D. V. (1922). On the Measurement of Buffer Values and on the Relationship of Buffer Value to the Dissociation Constant of the Buffer and the Concentration and Reaction of the Buffer Solution. J. Biol. Chem. 52, 525-570. Available at: http://www.jbc.org/content/52/2/525 [Accessed September 3, 2018].

Somero, G. N., and Childress, J. J. (1980). A Violation of the Metabolism-Size Scaling Paradigm: Activities of Glycolytic Enzymes in Muscle Increase in Larger-Size Fish. Physiological Zoology 53, 322-337. doi:10.1086/physzool.53.3.30155794.

Stephens, N., Di Silvio, L., Dunsford, I., Ellis, M., Glencross, A., and Sexton, A. (2018). Bringing cultured meat to market: Technical, socio-political, and regulatory challenges in cellular agriculture. Trends in Food Science \& Technology 78, 155-166. doi:10.1016/j.tifs.2018.04.010.

Suja, C. P., and Dharmaraj, S. (2005). In vitro culture of mantle tissue of the abalone Haliotis varia Linnaeus. Tissue and Cell 37, 1-10. doi:10.1016/j.tice.2004.08.002.

Suja, C. P., Sukumaran, N., and Dharmaraj, S. (2007). Effect of culture media and tissue extracts in the mantle explant culture of abalone, Haliotis varia Linnaeus. Aquaculture 271, 516-522.

Tacon, A. G. J., and Metian, M. (2008). Global overview on the use of fish meal and fish oil in industrially compounded aquafeeds: Trends and future prospects. Aquaculture 285, 146-158. doi:10.1016/j.aquaculture.2008.08.015. 
Taylor, I. W., and Hodson, P. J. (1984). Cell cycle regulation by environmental pH. Journal of cellular physiology $121,517-525$.

Tong, S., and Miao, H.-Z. (1996). Attempts to initiate cell cultures from Penaeus chinensis tissues. Aquaculture 147, 151-157.

Trummer, E., Fauland, K., Seidinger, S., Schriebl, K., Lattenmayer, C., Kunert, R., et al. (2006). Process parameter shifting: Part I. Effect of DOT, $\mathrm{pH}$, and temperature on the performance of Epo-Fc expressing CHO cells cultivated in controlled batch bioreactors. Biotechnology and Bioengineering 94, 1033-1044. doi:10.1002/bit.21013.

Tuomisto, H. L., Ellis, M. J., and Haastrup, P. (2014). Environmental impacts of cultured meat: alternative production scenarios. in Proceedings of the 9th international conference on life cycle assessment in the agri-food sector, 8-10.

Tuomisto, H. L., and Teixeira de Mattos, M. J. (2011). Environmental impacts of cultured meat production. Environmental science \& technology 45, 6117-6123.

Vaquer-Sunyer, R., and Duarte, C. M. (2008). Thresholds of hypoxia for marine biodiversity. PNAS 105, 15452-15457. doi:10.1073/pnas.0803833105.

Venugopal, T., Anathy, V., Kirankumar, S., and Pandian, T. J. (2004). Growth enhancement and food conversion efficiency of transgenic fish Labeo rohita. Journal of Experimental Zoology Part A: Comparative Experimental Biology 301A, 477-490. doi:10.1002/jez.a.78.

Verde, C., Giordano, D., and di Prisco, G. (2008). The adaptation of polar fishes to climatic changes: structure, function and phylogeny of haemoglobin. IUBMB life 60, 29-40.

Waltz, E. (2017). First genetically engineered salmon sold in Canada. Nature News 548, 148. doi:10.1038/nature.2017.22116.

Wang, J., Honda, H., Park, Y. S., Iijima, S., and Kobayashi, T. (1994). "Effect of Dissolved Oxygen Concentration on Growth and Production of Biomaterials by Animal Cell Culture," in Animal Cell Technology: Basic \& Applied Aspects: Proceedings of the Sixth International Meeting of the Japanese Association for Animal Cell Technology, Nagoya, Japan, November 9-12, 1993 The Sixth International Meeting of Japanese Association for Animal Cell Technology JAACT'93., eds. T. Kobayashi, Y. Kitagawa, and K. Okumura (Dordrecht: Springer Netherlands), 191-195. doi:10.1007/978-94-011-0848-5_28.

Wolf, K., and Mann, J. A. (1980). Poikilotherm vertebrate cell lines and viruses: A current listing for fishes. In Vitro 16, 168-179. doi:10.1007/BF02831507.

Wu, T., Zivanovic, S., Draughon, F. A., and Sams, C. E. (2004). Chitin and chitosan value-added products from mushroom waste. Journal of agricultural and food chemistry 52, 7905-7910.

Yamamoto, Y., Fujisawa, A., Hara, A., and Dunlap, W. C. (2001). An unusual vitamin E constituent ( $\alpha$-tocomonoenol) provides enhanced antioxidant protection in marine organisms adapted to cold-water environments. Proc Natl Acad Sci U S A 98, 13144-13148. doi:10.1073/pnas.241024298.

Yeo, S. E., Binkowski, F. P., and Morris, J. E. (2004). Aquaculture Effluents and Waste By-Products Characteristics, Potential Recovery, and Beneficial Reuse.

Zaraska, M. (2013). Lab-grown beef taste test: 'Almost'like a burger. The Washington Post.

Zhang, Z., Ju, Z., Wells, M. C., and Walter, R. B. (2009). Genomic approaches in the identification of hypoxia biomarkers in model fish species. Journal of experimental marine biology and ecology 381, S180-S187.

Zhao, F., and Ma, T. (2005). Perfusion bioreactor system for human mesenchymal stem cell tissue engineering: dynamic cell seeding and construct development. Biotechnol. Bioeng. 91, 482-493. doi:10.1002/bit.20532.

Zhao, Z., Montgomery-Brock, D., Lee, C.-S., and Lu, Y. (2003). Establishment, characterization and viral susceptibility of 3 new cell lines from snakehead, Channa striatus (Blooch). Methods Cell Sci 25, $155-166$. 
Zhu, M. M., Goyal, A., Rank, D. L., Gupta, S. K., Boom, T. V., and Lee, S. S. (2005). Effects of elevated pCO2 and osmolality on growth of CHO cells and production of antibody-fusion protein B1: a case study. Biotechnology progress 21, 70-77. 